\title{
Pelatihan Penggunaan "Kahoot" dalam Mengajar Reading Narrative bagi Siswa Kelas X SMA Veteran 1 Sukoharjo
}

\section{Training on the Use of Kahoot in Teaching Reading Narrative for Class X Students SMA Veteran 1 Sukoharjo}

\author{
Veronika Unun Pratiwi*1, Purwani Indri Astuti ${ }^{2}$, Nurnaningsih $^{3}$, Arin Arianti ${ }^{4}$, Mas \\ Sulis Setiyono \\ Universitas Veteran Bangun Nusantara Sukoharjo, Sukoharjo, Indonesia \\ *Penulis Korespondensi \\ 1pratiwiunun@yahoo.co.id, ${ }^{2}$ indripuspo@gmail.com
}

Riwayat Artikel: Dikirim 13 Januari 2021; Diterima 31 Mei 2021; Diterbitkan 31 Mei 2021

\begin{abstract}
Abstrak
Di masa pandemi ini semua sektor menjadi terpuruk, bahkan sektor pendidikan, yang notabene terbiasa dengan kelas face to face menjadi diwajibkan kelas offline atau daring. Maka, guru Bahasa Inggris dituntut juga untuk lebih kreatif dalam mengembangkan media pembelajaran. Bahasa Inggris memang berstatus sebagai mata pelajaran wajib, namun hasil yang didapat dari pelajaran Bahasa Inggris belum memuaskan. Kegiatan pembelajaran merupakan salah satu tahap yang menjadi penentu keberhasilan belajar siswa. Kualitas pendidikan dan pengajaran dapat ditingkatkan dengan mengoptimalkan sejumlah elemen, di antaranya yaitu siswa, guru, indikator pembelajaran, isi pelajaran, metode, media, dan evaluasi. Karena pentingnya materi reading bagi siswa, maka team pengabdian Universitas Veteran Bangun Nusantara Sukoharjo menawarkan pelatihan aplikasi Kahoot bagi siswa kelas X SMA Veteran 01 Sukoharjo. Metode yang diterapkan dalam metode ini berupa quiz. yang diajarkan kepada siswa kelas X disesuaikan RPP dan silabus siswa kelas X, serta materi reading yang diberikan. Target yang dicapai dari pengabdian ini adalah meningkatkan pengetahuan serta pengamahan tentang pelatihan reading dengan media Kahoot bagi siswa kelas X SMA Veteran 01 Sukoharjo. Selain itu, pengabdian ini diharapkan mampu menghasilkan beberapa hal yang hendak dicapai, di antaranya: (1) guru lebih memahami kemampuan tiap-tiap siswa dalam pemahaman reading; (2) guru dapat berpikir logis dan sistematis dengan memanfaatkan media yang ada dalam menjawab quiz. melalui pelatihan reading; (3) siswa diberikan asistensi untuk berpikir dengan didasarkan pada sudut pandang dalam praktik berpikir; (4) guru mampu meningkatkan kemampuannya dalam menumbuhkan motivasi siswa sehingga mereka tergerak untuk belajar; dan (5) siswa andil secara aktif dalam merencanakan dan mengelola kelas.
\end{abstract}

Kata kunci: bahasa Inggris, reading, Kahoot.

\begin{abstract}
During this pandemic, all sectors have collapsed, even the education sector, which is accustomed to face-to-face classes, has become mandatory for offline or online classes, so English teachers are also required to be more creative in developing learning media. Although English is a compulsory subject, the results attained from English subject are not very satisfying. Learning activities is one of the stages that determines the success of student learning. The quality of education and teaching can be enhanced by optimizing several elements such as students, teachers, learning indicators, lesson content, methods, media, and evaluation. Because of the importance of reading material for students, the Bangun Nusantara Sukoharjo Veteran University service team offers Kahoot application training for class X SMA Veteran 01 Sukoharjo. The method utilizsd in this method is a quiz, that is taught to class $X$ students according to the lesson plans and syllabus of class $X$ students, as well as the reading material given. The target to be achieved from this service is to increase knowledge and instruction about reading training using Kaboot media for class X SMA $V$ eteran 01 Sukoharjo. In addition, this dedication is expected to be able to achieve several things, nemely: (1) the teacher knows more about the ability of each student in reading comprehension; (2) teachers can think logically and systematically by utilizing existing media in answering quizzes through reading training; (3) students are assisted in learning to think. from a point of view in thinking practice; (4) teachers can further develop students' motivation to learn; and (5) students are actively involved in class planning and management.
\end{abstract}

Keywords: English language, reading, Kahoot. 


\section{PENDAHULUAN}

\section{Analisis Situasi}

Bahasa Inggris merupakan bahasa yang sampai sekarang tetap eksis sebagai bahasa internasional yang dipergunakan oleh banyak orang untuk berkomunikasi. Praktik pemakaian bahasa Inggris terbilang krusial, oleh karenanya bahasa Inggris dipertimbangkan oleh pemerintah untuk dijadikan sebagai bahasa asing yang digunakan di Indonesia untuk pertama kalinya sebab bahasa ini mempunyai peran esensial dalam tujuan pengembangan ilmu pengetahuan, teknologi, dan budaya. Di samping itu, bahasa Inggris dapat dipergunakan sebagai bahasa yang memudahkan komunikasi dalam menumbuhkan kerja sama internasional (Depdikbud, 1981). Terdapat empat skills dalam pembelajaran bahasa Inggris, yakni mencakup reading, writing, speaking, dan listening, di mana semua skills tersebut saling berkaitan dan selalu beriringan.

Salah satu hal yang tergolong krusial untuk diajarkan di era informasi dan globalisasi saat ini adalah reading atau pengajaran membaca bahasa Inggris. Pemerintah sadar akan urgensinya pembelajaran bahasa Inggris yang dapat diterapkan dalam berkomunikasi. Oleh sebab itu, pemerintah menetapkan UndangUndang Republik Indonesia No. 2 Tahun 1989 tentang Sistem Pendidikan Nasional yang dilanjutkan dengan Peraturan Pemerintah No. 28 Tahun 1990 tentang pengembangan sumber daya manusia (SDM). Pengembangan SDM dalam ranah edukasi dimanifestasikan dalam bentuk kegiatan yang dapat mengembangkan dan meningkatkan kualitas kompetensi dan keterampipan guru, siswa, dan tenaga kependidikan yang terkait.

Bahasa Inggris pada dasarnya sangat diperlukan bagi perkembangan peserta didik untuk ke depannya, sehingga diharapkan siswa mampu menguasai bahasa Inggris yang meliputi empat skills yakni listening, reading, speaking, dan reading. Dengan menguasai keempat skills tersebut, siswa tidak lagi merasa kesulitan bilamana mereka menempuh studi ke jenjang yang lebih tinggi. Di samping itu, di era milenial ini sekaligus di masa pandemi ini, pengajar dituntut untuk lebih aktif mengajar melalui daring atau offline, sehingga mau tidak mau para pengajar mempunyai kesempatan untuk menggunakan segala media untuk mendukung sistem KBM yang ada saat ini.

Berdasarkan pertimbangan di atas, Bahasa Inggris termasuk mata pelajaran yang diajarkan di SMA, di jenjang yang lebih tinggi sebelum masuk ke perguruan tinggi. Oleh sebab itu, siswa pun dituntut untuk lebih mempunyai kreativitas dalam menerima pembelajaran, apalagi saat ini mau tidak mau pembelajaran dilakukan dengan sistem daring dan aplikasi yang diunggah di HP siswa. Tujuan dari pemberian media online dalam belajar Bahasa Inggris ini adalah untuk memberi motivasi serta menyiapkan siswa agar siap dan yakin dalam mempelajari bahasa Inggris ditingkat yang lebih tinggi, yaitu perguruan tinggi. Kendati demikian dalam pengajaran bahasa Inggris di tingkat SMA, siswa perlu memiliki pengetahuan perihal merangkai kata menjadi kalimat yang mempunyai koherensi antar kalimat. Hal inilah yang dijadikan fokus dalam pembelajaran reading sebagai salah satu skills dalam bahasa Inggris yang harus dikuasai selain speaking, writing, listening, dan vocabulary.

Sekolah yang menjadi target tim pengabdian adalah SMA Veteran 1 Sukoharjo. Sekolah ini merupakan sekolah yang sudah lama berdiri dan kebetulan satu atap dengan Univet Bantara, di mana dilihat dari peminatnya siswa di SMA Veteran 1 ini tergolong sedikit namun pihak sekolah dan Yayasan selalu bekerja keras untuk memajukan sekolah ini meskipun kecil namun berprestasi. Di sisi lain sistem KBMnya juga sudah mulai daring namun karena sesuatu yang dipaksakan mengakibatkan siswa juga belum terlalu siap dengan dilihat dari nilai yang didapat, serta kesalahankesalahan yang siswa buat, maka tim pengabdian tergerak untuk memberikan 
pelatihan penggunaan media Kahoot untuk membantu siswa belajar reading narrative text.

\section{Permasalahan Mitra}

SMA Veteran 1 Sukoharjo letaknya tidak jauh dari pusat Kota Sukoharjo, yakni terletak di Jl. Dokter Muwardi No. 84, Sawahm Gayam, Kecamatan Sukoharjo, Kabupaten Sukoharjo. Dengan dipimpin Bapak Sugiyarto, sekolah ini memiliki 21 guru, 116 siswa laki-laki, dan 204 siswa perempuan, memiliki 12 rombel atau rombongan belajar, dan menggunakan kurikulum 13 sebagai acuannya. Di samping itu, SMA Veteran 1 ini memiliki akreditasi A (sekolah.data.kemendikbud.go.id).

Kendati siswanya belum seperti sekolah yang lain di Sukoharjo namun SMA Veteran 1 ini selalu berbenah untuk mendapatkan prestasi. Jumlah siswa SMA Veteran 01 sedang mengalami fluktuasi, yaitu statusnya sedang mengalami penurunan dari jumlah yang sebelumnya terbilang lebih tinggi. Kondisi ekonomi dari orang tua siwa termasuk variatif, yakni dari kalangan menegah ke bawah. Kebanyakan orang tua siswa hanya menempuh pendidikannya pada jenjang SMP dan SMA. Hanya sedikit dari mereka yang menyelesaikan pendidikannya pada tingkat sarjana (S1). Dalam pembelajaran bahasa, khususnya bahasa Inggris, ada empat skills yang sifatnya mutlak untuk dikuasai siswa, yakni: (1) keterampilan menyimak (listening), (2) keterampilan membaca pemahaman (reading), (3) keterampilan berbicara (speaking), dan (4) keterampilan menulis (writing), termasuk pemahaman kosakata (vocabulary). Penguasaan suatu skill dapat dicapai secara optimal apabila diiringi dengan pengajaran dan pelatihan yang tepat. Kemampuan penguasaan membaca dengan menerapkan media Kahoot pun perlu diajarkan. Pelatihan membaca yang menarik akan membuat siswa lebih tergerak untuk menyelami pembelajaran bahasa Inggris khususnya belajar membaca ini. Pelatihan membaca ini ada baiknya dilakukan secara kontinu sehingga diharapkan siswa mampu mengerjakan tugas reading dengan media Kahoot ini secara lancar.

Tim pengabdi memilih kelas X sebagai mitra karena dirasa kelas ini adalah kelas awal dalam memulai pembelajaran, sehingga siswa diharapkan bisa menguasai media Kahoot hingga nanti di tingkat kelas yang lebih tinggi. Tim memilih kelas $\mathrm{X}$ sebagai kelas beginner dalam mempelajari bahasa Inggris setelah mereka mendapatkan dari SMP. Pembelajaan bahasa Inggris menuntut para siswa terampil membaca serta memahami teks terutama teks yang diajarkan saat ini yakni teks narrative dalam proses KBM. Para siswa setidaknya berkemampuan dalam menyampaikan ideidenya atau pendapatnya, termasuk menjawab pertanyaan, serta mengikuti alur pemikirannya dalam bahasa lisan. Hal tersebut selain dipengaruhi oleh penguasaan vocabulary siswa, hal lainnya yang berpengaruh adalah cara siswa membaca atau mengemukakan suatu pendapat melalui bacaan. Namun data empiris mengindikasikan bahwa kemampuan siswa yang sudah belajar bahasa Inggris masih terbilang rendah. Hanya sebagian siswa yang bisa berbahasa Inggris dengan cukup baik. Rata-rata siswa ini bisa berbahasa Inggris dengan cukup baik, akan tetapi hampir separo siswa dalam pemahaman bahasa Inggris kurang begitu tertarik, sehingga nilai yang mereka dapatkan dalam penulisan bahasa Inggris tergolong buruk, di bawah KKM. Prestasi belajar para siswa SMA Veteran 1 Sukoharjo ini rata-rata sudah berkategori baik secara umum, tetapi hanya beberapa siswa yang nilainya bagus pada pelajaran bahasa Inggris, terutama bagi siswa yang menggunakan media untuk pertama kalinya. Permasalahan seperti inilah yang membuat tim pengabdian masyarakat tertarik untuk menjalankan pembinaan, khususnya pelatihan reading dengan mengajarkan media Kahoot yang mengajarkan siswa mengisi quiz yang menarik dan tidak membosankan. Melalui penggunaan media yang mudah, diharapkan siswa menjadi tertarik untuk belajar bahasa 
Inggris.

\section{Solusi yang Ditawarkan}

Berkenaan dengan permasalahan di atas, maka langkah yang diambil tim pengabdian pada masyarakat yaitu melalui pengadaan pelatihan reading dengan mengaplikasikan media Kahoot, di mana media Kahoot ini dapat membantu siswa memahami quiz, yang diberikan pada siswa sebelum mereka memasuki materi teks narrative yang akan diajarkan oleh guru. Paling tidak siswa mulai tertarik dulu untuk belajar bahasa Inggris dengan menggunakan media yang menarik pula. Tim pengabdian memilih media yang mudah dan bisa dipahami oleh siswa SMA yaitu reading dengan menggunakan media Kahoot yang menarik perhatian siswa, serta quiz dari media Kahoot yang sudah teraplikasi di dalam ponsel siswa. Kegiatan umum pelatihan ini diawali dengan penyuluhan untuk memberi pengenalan perihal media yang diaplikasikan dalam pembelajaran bahasa Inggris, khususnya media yang menggunakan online yaitu Kahoot, demonstrasi dengan memberikan contoh cara mempergunakan media Kahoot untuk menjawab quiz dari media Kahoot tersebut, dilanjutkan dengan pendampingan menggunakan media Kahoot sampai dinilai siswa cukup mampu belajar secara mandiri dalam hal ini tanpa dibimbing oleh guru bahasa Inggris mereka, terakhir dengan melakukan evaluasi untuk mengetahui seberapa jauh pengetahuan yang dimiliki para siswa mengenai materi reading dengan menggunakan media Kahoot yang telah dipahami siswa.

\section{Target}

Target yang ingin dicapai dari pengabdian ini adalah meningkatkan pengetahuan tentang pelatihan vocabulary dengan pembelajaran yang interaktif yaitu project-based learning bagi guru bahasa Inggris SDN Jombor 01. Selain itu pengabdian ini diharapkan mampu menghasilkan beberapa hal yang hendak dicapai, di antaranya: (1) guru lebih mengetahui kemampuan mereka dalam membuat media ajar yang inovatif; (2) guru dapat berpikir logis dan sistematis dengan memanfaatkan media yang ada dalam menciptakan tema pengajaran bahasa Inggris yang menarik sesuai kurikulum 2013; (3) siswa diasisteni untuk bisa belajar berpikir dengan berlandaskan pada sudut pandang dalam praktik berpikir; (4) guru dapat lebih menumbuhkan motivasi siswa untuk belajar; dan (5) siswa andil dalam merencanakan dan mengelola kelas.

\section{Luaran}

Luaran yang dihasilkan dalam kegiatan ini di antaranya: (1) artikel ilmiah untuk dipublikasikan dalam jurnal/prosiding; (2) kemampuan para guru bahasa Inggris menggunakan media yang inovatif, kreatif dan menarik dalam mengajar siswa. Agar kegiatan ini efektif, akan dilakukan pretest dan post test, dengan demikian dari hasil pretest dan posttest tersebut tim pengabdi dapat mengukur sampai di mana hasil belajar mitra.

\section{METODE}

Agar permasalahan yang dihadapi mitra dapat diatasi, maka disampaikan sejumlah solusi yang dapat direalisasi melalui beberapa kegiatan berikut ini:

\section{Penyuluhan}

Kegiatan ini mengacu pada pengadaan observasi awal atau orientasi lapangan mengenai pengetahuan siswa-siswi SMA Veteran 1 Sukoharjo secara daring dengan memberikan google form pada siswa tentang pengetahuan bahasa Inggris. Materi diberikan lewat pengenalan media yang diaplikasikan dalam pembelajaran Bahasa Inggris, khususnya media yang memakai IT, serta menjelaskan kepada siswa perihal kegiatan apa saja yang akan dilaksanakan oleh tim pengabdian yakni oleh Veronika Unun Pratiwi, S.Pd., M.Pd., selama sekitar 30 menit dengan aplikasi Zoom. 


\section{Demonstrasi}

Pengabdian ini berupa memberikan pelatihan tentang pelatihan reading dengan media Kahoot yang diulangi, dan memberi pertanyaan pada siswa dengan mengulang bagian-bagian cerita dan memberi pertanyaan, sehingga guru dapat melihat apakah siswa memahami aplikasi Kahoot. Kegiatan ini dilakukan oleh Mas Sulis Setiyono S.Pd, M.Hum. Langkah-langkah penerapan pelatihan reading dengan media Kahoot adalah sebagai berikut:

\section{Tahap 1: Penyampaian Kompetensi}

Pada tahap ini, tim pengabdi diekspektasikan mampu memberi paparan atau penyampaian perihal kompetensi dasar mata pelajaran yang bersangkutan. Siswa mampu menilai seberapa jauh penguasaan kompetensi yang harus dicapai. Tim pegabdi pun harus mampu memaparkan atau menginformasikan sejumlah indikator ketercapaian kompetensi agar tingkat keberhasilan siswa dalam meraihnya atau mencapainya dapat diukur.

\section{Tahap 2: Presentasi Materi}

Pada tahap penyajian materi, momentum awal pembelajaran telah selesai diciptakan oleh tim pengabdi. Pada tahap ini, tim pengabdi harus mampu menstimulus atau memunculkan dorongan pada sejumlah siswa yang dinilai belum menunjukkan kesiapan.

\section{Tahap 3: Penyampaian Media Kahoot secara online}

Pada tahap ini, tim pengabdi menyampaikan pentingnya media Kahoot dalam membantu pembelajaran reading narrative text bagi siswa kelas SMA Veteran 1 Sukoharjo. Tim pengabdi mengajak siswa untuk andil secara aktif dalam proses pembelajaran dengan mencermati secara saksama mengenai langkah-langkah penerapan media Kahoot. Melalui media online, pengajaran akan menjadi hemat energi dan memunculkan minat dalam diri siswa sehingga mereka tergerak untuk terlibat aktif dalam proses pembelajaran. Di samping itu, materi yang disampaikan akan dapat dengan mudah dipahami oleh siswa. Pada perkembangan berikutnya, guru dapat memodifikasi media Kahoot untuk mengajar serta mengaplikasikannya dalam skill yang lain.

\section{Tahap 4: Peragaan Media Kahoot}

Pada tahap ini, siswa akan ditunjuk dan dipanggil secara bergiliran oleh tim pengabdi untuk media Kahoot dengan menjawab quiz, yang ada dalam media Kahoot yang berhubungan dengan materi reading narrative. Kemudian siswa mulai mencoba mempraktikkan media Kahoot yang telah teraplikasi.

\section{Tahap 5: Penjajakan}

Pada tahap ini, tim pengabdi diharuskan menanyai siswa perihal hal-hal yang melatari atau mendasari gagasan di balik penerapan media Kahoot. Kemudian tim pengabdi mengajak siswa untuk mencari rumus, tuntutan kompetensi dasar yang dilandaskan pada indikator-indikator yang hendak diraih.

\section{Tahap 6: Penyajian Kompetensi}

Pada tahap ini, ketercapaian kompetensi harus dapat ditekankan oleh tim pengabdi. Hal-hal yang dapat dilakukan tim pengabdi di antaranya yaitu memberi penjelasan, pengulangan, dan penceritaan ulang perihal penggunaan media Kahoot sehingga siswa memahami pentingnya penerapan media tersebut dalam pencapaian kompetensi dasar dan sejumlah indikator yang sudah ditentukan.

\section{Tahap 7: Penutup}

Di akhir pembelajaran, siswa dan tim pengabdi saling melakukan refleksi mengenai apa yang sudah dicapai dan dilaksanakan. Hal tersebut ditujukan agar dapat menguatkan materi ataupun kompetensi siswa dalam mengingat media yang pengajarannya dilakukan secara daring. 


\section{Pendampingan}

Pendampingan dilaksanakan selama lima bulan, yaitu mulai dari bulan September sampai bulan Januari 2020. Tim Pengabdian mendatangi SMA Veteran 1 Sukoharjo sebagai mitra belajar dan pelaksanaan kegiatan ini dijalankan secara kontinu.

\section{Evaluasi}

Evaluasi dilakukan melalui pre-test dan post-test. Pre-test mengaplikasikan questionnaire yang pembagiannya atau penyebarannya dilakukan secara daring dan ditujukan untuk mengetahui sejauh mana pengetahuan para siswa tentang materi reading yang telah mereka pahami, yakni dilakukan oleh Purwani Indri Astuti, S.S., M.Hum di mana pelaksanaannya berlangsung selama 15 menit. Usai dilakukan kegiatan penyuluhan dan pelatihan, tim pengabdi melakukan evaluasi dengan mengaplikasikan questionnaire yang ditujukan agar dapat melihat kemajuan dan peningkatan pengetahuan para siswa mengenai pemahaman materi reading, yakni dilakukan oleh Arin Arianti, S.Pd., M.Pd., selama 15 menit.

\section{KELAYAKAN PERGURUAN TINGGI}

Kelayakan PT ini terdiri dari dua bab di mana keduanya tidak bisa terpisahkan. Alasannya adalah sub kedua tidak bisa lepas dari sub yang pertama.

\section{Pengalaman Perguruan Tinggi dalam Pengabdian Kepada Masyarakat}

Lembaga Penelitian dan Pengabdian kepada Masyarakat (LPPM) Universitas Veteran Bangun Nusantara (UNIVET BANTARA) Sukoharjo sebagai salah satu unit pelaksana tugas deseminasi dan pengabdian kepada masyarakat memiliki tanggung jawab untuk mengkoordinir, memonitor, mengevaluasi dan mengembangkan deseminasi serta pengabdian kepada masyarakat para dosen sesuai dengan regulasi. Selain itu LPPM Univet Bantara juga mengelola pelaksanaan Kuliah Kerja Nyata (KKN) yang rutin diselenggarakan setiap tahun.

Sebagai lembaga pelaksana programprogram deseminasi maupun programprogram pengabdian kepada masyarakat (PkM) LPPM Univet Bantara Sukoharjo mendokumentasi kinerjanya dalam bentuk Laporan Kinerja Deseminasi dan Pengabdian kepada Masyarakat yang disusun setiap tahun. Gambaran Kinerja LPPM Univet Bantara dalam kegiatan Produk Teknologi yang didesiminasikan dalam 3 tahun terakhir antara lain sebagai berikut:

\section{Tabel 1:}

Tabel Kinerja LPPM Univet Bantara Sukoharjo

\begin{tabular}{|l|l|l|l|}
\hline No. & Nama Produk/Inovasi & Nama Dosen & Tahun \\
\hline 1 & $\begin{array}{l}\text { Cabboxymetyl Cellulose (CMC) Food } \\
\text { Grade Selulosa Batang Tanaman Jagung }\end{array}$ & $\begin{array}{l}\text { Novian Wely Asmoro } \\
\text { dan afriyanti }\end{array}$ & 2017 \\
\hline 2 & $\begin{array}{l}\text { Minuman Fermentasi Laktat Probiotik } \\
\text { Lokal }\end{array}$ & Agustina Niken Tari & 2017 \\
\hline 3 & $\begin{array}{l}\text { Model Media Sosial dan Content Iklan } \\
\text { Media Sosial yang Sukses bagi Produk } \\
\text { Unggulan UKM }\end{array}$ & Joko Suryono & 2017 \\
\hline 4 & Yoghurt Sinbiotik Kering Beku & Agustina Niken Tari & 2018 \\
\hline 5 & $\begin{array}{l}\text { Dokumen Arkeologi di Museum Rumah } \\
\text { Arca Kabupaten Sukoharjo }\end{array}$ & Andriyanto & 2018 \\
\hline 6 & Media Pembelajaran Berbasis Android & Singgih Subiyantoro & 2018 \\
\hline 7 & $\begin{array}{l}\text { Gelatin limbah tulang ayam sebagai } \\
\text { antimicrobial edible film dengan ekstrak } \\
\text { daun the }\end{array}$ & LudfiaA Windyasmara & 2018 \\
\hline 8 & $\begin{array}{l}\text { Game edukatif sebagai media bimbingan } \\
\text { teori-teori konseling }\end{array}$ & Bambang Susanto & 2018 \\
\hline 9 & Pupuk Bokasih & Sudarmi & 2019 \\
\hline 10 & $\begin{array}{l}\text { Sereal Sarapan dari Tepung Mocaf dan } \\
\text { Tepung Daun Kelor }\end{array}$ & $\begin{array}{l}\text { Novian Wely Asmoro, } \\
\text { Agustina Niken Tari, } \\
\text { Retno Widyastuti }\end{array}$ & 2019 \\
\hline 11 & Disk Modul Berbasis Lesson Study & Herry Agus Susanto & 2019 \\
\hline 12 & $\begin{array}{l}\text { Model Pendidikan Karakter Melalui } \\
\text { Literasi Berbasis Ekranisasi }\end{array}$ & Farida Nugrahani & 2019 \\
\hline 13 & $\begin{array}{l}\text { lbM Pelathan Bahasa Jawa dan Bahasa } \\
\text { Inggris bagi Tukang Kuda di daerah wisata } \\
\text { Tawang Mangu }\end{array}$ & Veronika Unun Pratiwi & 2017 \\
\hline 14 & Pengolahan Limbah RPH & Catur Rini S & 2018 \\
\hline
\end{tabular}

\section{Kualifikasi Tim Pelaksana}

Tabel 2:

Tabel Tim Pelaksana

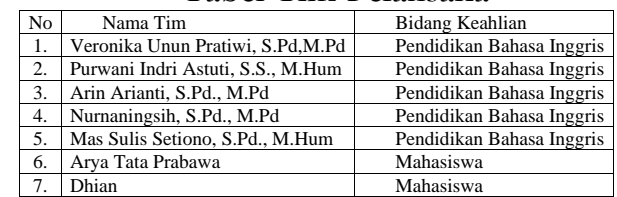

Kualifikasi tim pelaksana tersebut diharapkan dapat menyelesaikan pemasalahan mitra dengan pembagian tugas pada tiap tahap pelaksanaannya yang sudah terperinci dengan jelas. 


\section{HASIL DAN PEMBAHASAN}

Dari hasil kegiatan tim pengabdian pada masyarakat Univet Bantara Sukoharjo, tim pengabdian mendapatkan hasil yang memuaskan, di mana Pelatihan Penggunaan 'Kahoot' Dalam Mengajar Reading Narrative Bagi Siswa Kelas X SMA Veteran 1 Sukoharjo ini bisa diterima baik oleh mitra, bahkan mitra mulai merasa tertarik dan antusias untuk mengikuti pelatihan Kahoot ini dalam pembelajaran Bahasa Inggris. Mitra sudah mengenal media pembelajaran namun mereka baru kali ini berlatih mengguakan Kahoot yang meurut mereka sangat menarik.

\section{Hasil}

1) Siswa andil secara aktif dalam proses pembelajaran dengan mencermati secara saksama mengenai langkah-langkah penerapan media Kahoot.

2) Pengajaran menjadi hemat energi dan memunculkan minat dalam diri siswa sehingga mereka tergerak untuk terlibat aktif dalam proses pembelajaran.

3) Di samping itu, materi yang disampaikan akan dapat dengan mudah dipahami oleh siswa.

4) Pada perkembangan berikutnya, guru dapat memodifikasi media Kahoot untuk mengajar serta mengaplikasikannya dalam skill yang lain

\section{Pembahasan}

1) Siswa andil secara aktif di dalam proses pembelajaran.

Hal ini dapat dilihat dari beberapa kali pelatihan, mitra mulai mengenal media Kahoot ini dengan baik. Bahkan dalam pembelajaran Bahasa Inggris mitra tidak merasakan kesulitan; mereka tertantang untuk menggunakan media Kahhot ini untuk pembelajaran lain selain Bahasa Inggris. Siswa menginginkan pembeljaran bahasa Inggris lebih banyak menggunakan media pembelajaran yang menarik seperti Kahoot ini.
2) Pengajaran menjadi hemat energi dan memunculkan minat dalam diri siswa sehingga mereka tergerak untuk terlibat aktif.

Hemat energi karena guru tidak perlu mengevaluasi dan memberi penilaian karena Kahoot sudah memberikan skor langsung kepada hasil pekerjaan mitra. Kahoot memunculkan minat dalam diri siswa sehingga mereka tergerak untuk terlibat aktif. disebabkan oleh adanya pembelajaran yang disertai permainan dalam bentuk quiz yang menghitung skor siswa yang paling tinggi hingga juara ke 3 . Sehingga membuat mitra tertarik belajar bahasa Inggris dan berpartisipasi aktif dalam proses pembelajaran tersebut.

3) Materi yang disampaikan akan dapat dengan mudah dipahami oleh mitra.

Hal yang membuat materi mudah difahami mitra adalah dengan meminta mitra memeperhatikan dan mengingat ingat materi yang disampaikan tanpa merasa tertekan atau terpaksa karena adanya permainan yang menumbuhkan semangat bersaing supaya bisa menjadi juara 1 dan tidak menjadi yang terbelakang. Semanata bersaing yang ditumbuhkan oleh Kahoot tersebut telah menumbuhkan keinginan mitra untuk benar-benar menguasai materi dan tidak tertinggal dengan teman-teman yang lain.

4) Pada perkembangan berikutnya, guru dapat memodifikasi media Kahoot untuk mengajar serta mengaplikasikannya dalam skill yang lain.

Dalam pelatihan media Kahoot ini guru Bahasa Inggrisnya pun ikut terlibat dan sangat antusias mengikuti dan mendampingi siswanya yang notabene sebagai mitra pelatihan. Guru bahasa Inggris kelas tersebut dapat mengganti soal yang telah digunakan diganti dengan materi lain yang akan digunakan dimpertemuan selanjutnya. Selain itu, guru juga dapat mengkobinasikan Kahoot dengan media pembelajaran yang lain sepeti video pembelajaran yang di download dari Youtube ayng selanjutnya 
digunakan sebagai media ntuk menerangkan materi kepada siswa. Kemudian, Kahoot digunkan sebagai media untuk mengevaluasi materi yang telah diterangkan.

Luaran yang dihasilkan dari pengabdian ini adalah peningkatan kemampuan mitra dalam menggunakan media Kahoot dalam pembelajaran Reading Narrative text dengan kriteria yang telah ditetapkan dan dilatihkan. Tim pengabdi juga membuat artikel pengabdian ini untuk diterbitkan di jurnal pengabdian.

\section{KESIMPULAN}

Berdasarkan hasil kegiatan pengabdian pada masyarakat tentang Pelatihan Penggunaan 'Kahoot' Dalam Mengajar Reading Narrative Bagi Siswa Kelas X SMA Veteran 1 Sukoharjo ini, dapat dikatakan berhasil karena kemampuan mitra dalam menggunakan media ini bisa dilihat dari hasil pelatihan dan pendampingan yang mitra peroleh. Di sisi yang lainnya guru bahasa Inggris terbantu dengan adanya pelatihan ini.

\section{DAFTAR PUSTAKA}

Basuki, Yudi \& Hidayati, Y. N. (2019). Kahoot! Or Quizizz: the Students' Perspective. In Proceedings of the $3 \mathrm{rd}$ English Language and Literature International Conference (ELLiC) (pp. 202-211). Semarang: Faculty of Foreign Language and Culture Universitas Muhammadiyah Semarang. Retrieved from https://books.google.co.id/books?id= ¡FAIEAAAQBAJ\&printsec $=$ frontcov er\&dq $=$ Ellic $+2019 \& \mathrm{hl}=\mathrm{id} \& \mathrm{sa}=\mathrm{X} \& \mathrm{ve}$ $\mathrm{d}=2 \mathrm{ahUKEwjPr}-$

CW IzvAhXQXSsKHZ3iBmoQ6AE wAHoECAEQAw $\#_{\mathrm{v}}=$ onepage\&q $=\mathrm{E}$ $\underline{1 \text { lic } \% 202019 \& \mathrm{f}=\text { false }}$

Brown, Douglas H. (1987). Principle of Language Learning and Teaching. Englewood Cliffs, New Jersey: Prentice Hall Regents.

Chiang, H. (2020). Kahoot! In an EFL Reading Class. Journal of Language
Teaching and Research, 11(1), pp. 33-44. Retrieved from https://www.academypublication.com Lojs/index.php/jltr/article/view/jltr1 1013344

Hymes, Dell. (1988). Foundation in Sociolingusitics: an Etnographic Approach. Philadelphia: University of Pennsylvania Press.

Irwan, I., Luthfi, Z. F., \& Waldi, A. (2019). Efektifitas Penggunaan Kahoot! untuk Meningkatkan Hasil Belajar Siswa [Effectiveness of Using Kahoot! to Improve Student Learning Outcomes]. PEDAGOGIA: Jurnal Pendidikan, 8(1), pp. 95-104. Retrieved from https://ojs.umsida.ac.id/index.php/pe dagogia/article/view/1866

Licorish, S. A., George, J. L., Owen, H. E., \& Daniel, B. (2017). "Go Kahoot!" Enriching Classroom Engagement, Motivation and Learning Experience with Games. In Proceedings of the 25th International Conference on Computers in Education (pp. 755-764). Semarang: Faculty of Foreign Language and Culture Universitas Muhammadiyah Semarang. Retrieved from https://www.researchgate.net/profile /Sherlock Licorish/publication/3221 50947 Go Kahoot Enriching Classr oom Engagement Motivation and L earning Experience with Games/link s/5a484fd80f7e9ba868ab622d/Go-

Kahoot-Enriching-ClassroomEngagement-Motivation-andLearning-Experience-with-Games.pdf Licorish, S. A., Owen, H. E., Daniel, B., \& George, J. L. (2018). Students' perception of Kahoot!'s influence on teaching and learning. Research and Practice in Technology Enhanced Learning, 13(9). Retrieved from https://telrp.springeropen.com/article $\mathrm{s} / 10.1186 / \mathrm{s} 41039-018-0078-8$

Plump, C. M. \& LaRosa, J. (2017). Using Kahoot! in the Classroom to Create Engagement and Active Learning: A Game-Based Technology Solution for 
eLearning Novices. Management Teaching Review, 2(2), pp. 151-158. Retrieved from

https://journals.sagepub.com/doi/full $\angle 10.1177 / 2379298116689783$

Rivers, W. (1993). Communicating Naturally in a Second Language. Cambridge: Cambridge University Press.

Wang, A. I. \& Tahir, R. (2020). The effect of using Kahoot! for learning - A literature review. Computer \& Education, 149, 103818. Retrieved from https://www.sciencedirect.com/scien ce/article/pii/S0360131520300208

Wardhaugh, Ronald. (1998). An Introduction to Sociolinguitics. Oxford: Blackwell Publishers Ltd. 